NASA TECHNICAL NOTE

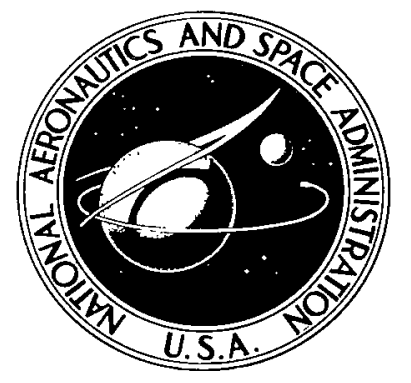

NASA IN D-6040 C. 1

LOAN COPY: RETL 믄

AFWL (WLOL KIRTLAND AFB, 满

\title{
PLANE ELASTOSTATIC ANALYSIS OF V-NOTCHED PLATES
}

by Bernard Gross and Alexander Mendelson

Lewis Research Center

Cleveland, Obio 44135

NATIONAL AERONAUTICS AND SPACE ADMINISTRATION - WASHINGTON, D. C. - OCTOBER 1970 
1. Report No.

NASA TN D -6040

4. Title and Subtitle

PLANE ELASTOSTATIC ANALYSIS OF V-NOTCHED PLATES

7. Author(s)

Bernard Gross and Alexander Mendelson

9. Performing Organization Name and Address

Lewis Research Center

National Aeronautics and Space Administration

Cleveland, Ohio 44135

12. Sponsoring Agency Name and Address

National Aeronautics and Space Administration

Washington, D. C. 20546

15. Supplementary Notes

16. Abstract

Solutions are given for several plane elastostatic problems of plates having a $v$-notch on one edge, and subjected to a variety of boundary conditions. The effect of the magnitude of the v-notch angle and specimen geometry on stress intensity factors $\mathrm{K}_{\mathrm{I}}$ and $\mathrm{K}_{\Pi}$ are obtained for unioaded notch surfaces. Examples are given of notch surface displacements for several selected cases. Analytical solutions are formulated but not computed for the case of a loaded notch surface or one with prescribed boundary surface displacements. Notch opening displacements at the plate edge were measured experimentally and the results obtained were in excellent agreement with the com puted results

17. Key Words (Suggested by Author(s))

Fracture mechanics

Stress-intensity factor

Fracture toughness

$\mathrm{V}$-notch

19. Security Classif. (of this report)

Unclassified
18. Distribution Statement

Unclassified - unlimited

* For sale by the Clearinghouse for Federal Scientific and Technical Information

Springfield, Virginia 22151 


\section{PLANE ELASTOSTATIC ANALYSIS OF V-NOTCHED PLATES \\ by Bernard Gross and Alexander Mendelson \\ Lewis Research Center}

\section{SUMMARY}

Solutions are given for several plane elastostatic problems of plates having a $\mathrm{v}$-notch on one edge, and subjected to a variety of boundary conditions. The effect of the mag-

nitude of the $\mathrm{v}$-notch angle and specimen geometry on stress intensity factors $\mathrm{K}_{\mathrm{I}}$ and $\mathrm{K}_{\mathrm{II}}$ are obtained for unloaded notch surfaces. Examples are given of notch surface displacements for several selected cases. Analytical solutions are formulated but not computed for the case of a loaded notch surface or one with prescribed boundary surface displacements.

Notch opening displacements at the plate edge were measured experimentally and the results obtained were in excellent agreement with the computed results.

\section{INTRODUCTION}

Knowledge of the stress distribution in the neighborhood of a singularity, such as at the tip of a $v$-notch in a loaded plate is of fundamental importance in evaluating the resistance to quasi-brittle fracture of structural materials. Many different types of specimens have been used in fracture toughness tests. However, for several reasons connected with optimization of specimen size and load requirements (ref. 1) single edge crack plate specimens loaded in tension or bending are of current interest from the standpoint of fracture test method development (ref. 2).

An analytical solution for a finite width single edge crack specimen loaded in tension was given by Gross, Srawley, and Brown (ref. 3), using boundary collocation techniques applied to an appropriate stress function derived by Brahtz (ref. 4) and Westergaard (ref. 5) and independently by Williams (refs. 6 and 7). Solutions for other finite width edge cracked specimens subject to bending or combinations of tension and bending were subsequently obtained by Gross and Srawley (refs. 8 to 12). The results are in good agreement with those obtained experimentally (refs. 13 to 15 and unpublished data by Jones, Bubsey, and Brown of Lewis) and analytically by other methods (refs. 16 to 19), as shown in detail in reference 19. 


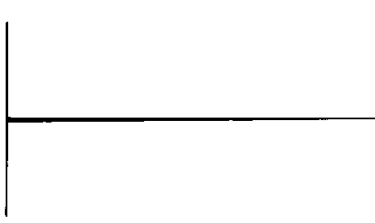

(a) Ideal plane crack.

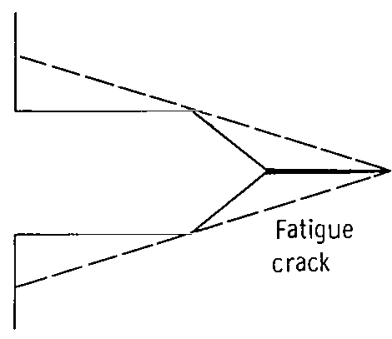

(b) Machined notch.

Figure 1. - In practical specimens the ideal plane crack (a) is simulated by a machined notch with a fatigue crack extension (b). The dashed lines represent a sharp, finite-angle notch which just includes the machined notch and fatigue crack extension.

The specimens recommended by ASTM Committee E-24 for plane strain fracture toughness tests (ref. 2) have machined notches tipped with fatigue cracks (fig. 1(b)) which are intended to represent ideal plane cracks (fig. 1(a)). For practical reasons it is desirable to allow considerable latitude in the form of the machined notch; the only important consideration is that the crack-tip stress field should not be significantly different from that of the ideal plane crack which is represented. To establish how much latitude in crack-notch configuration can be allowed it is sufficient to investigate the stress fields of pointed $v$-notches as a function of notch angle. Any crack-notch configuration can be just bounded by a v-notch of some angle which has its apex at the crack tip (fig. 1(b)). The deviation of the stress field of that $v$-notch from the stress field of a zero-angle notch (plane crack) is an upper bound on the deviation of the crack-notch configuration. Thus the $\mathrm{v}$-notch angle is useful as a single parameter for characterizing practical crack-notch configurations in relation to ideal crack-tip stress fields. The present work is concerned with the analysis of $v$-notched plates as a function of notch angle.

The first attempt at such an analysis was made in reference 20 for a restricted geometry, using the collocation procedures of Gross and Srawley (refs. 3 and 8). The present analysis gives the general solution over a broad range of geometries and in particular determines the influence of the notch angle on fracture toughness measurements.

The elastic stress and displacement solution of a homogeneous isotropic rectangular plate of finite dimensions with a v-notch loaded by either symmetric or antisymmetric loads is given. The necessary equations for the case of longitudinal shear (mode III) are developed but no quantitative solution given. 


\section{SYMBOLS}

The following list contains the commonly used symbols and their definitions. In general, all symbols are defined when introduced.

$A_{i, n}$

$\mathrm{a}, \mathrm{b}, \mathrm{h}, \mathrm{s}, \mathrm{w}$

E

G

$\mathrm{K}, \mathrm{K}_{\mathrm{I}}, \mathrm{K}_{\mathrm{II}}$

$\mathrm{K}_{\mathrm{C}}, \mathrm{K}_{\mathrm{IC}}, \mathrm{K}_{\mathrm{IIC}}$ M

$\mathbf{P}$

$\mathrm{u}_{\mathrm{r}}, \mathrm{u}_{\varphi}$

$\mathrm{u}_{\mathrm{x}}, \mathrm{u}_{\mathrm{y}}, \mathrm{u}_{\mathrm{z}}$

$\kappa$

$\lambda_{\mathrm{n}}=\eta_{\mathrm{n}}+\mathrm{i} \zeta_{\mathrm{n}}$

$\nu$

$\sigma_{\mathrm{e}}$

$\sigma_{\mathrm{r}}, \sigma_{\varphi}, \sigma_{\mathrm{z}}, \tau_{\mathrm{r} \varphi}$,

$\tau_{\mathrm{rz}}, \tau_{\varphi \mathbf{z}}$

$\sigma_{\mathrm{x}}, \sigma_{\mathrm{y}}, \sigma_{\mathrm{z}}, \tau_{\mathrm{xy}}$

$\tau_{\mathrm{yz}}, \tau_{\mathrm{zX}}$

$\tau$

$x$ coefficients of the stress function series associated with the $\mathrm{n}^{\text {th }}$ eigenvalue

specimen dimensions as shown in figs. 2 to 4

modulus of elasticity

shear modulus

stress intensity factor at the notch tip, subscript I, II refers to mode of notch extension

critical value of the stress intensity factor $K, K_{I}$, and $K_{\Pi}$

bending moment

applied load

displacements in the radial and tangential directions, respectively

displacements in $\mathrm{x}, \mathrm{y}$, and $\mathrm{z}$ directions, respectively

$\begin{cases}\nu /(1+\nu) & \text { for plane stress conditions } \\ \nu & \text { for plane strain conditions }\end{cases}$

$\mathrm{n}^{\text {th }}$ complex eigenvalue

Poissons ratio

equivalent stress

components of the stress tensor

$\mathrm{P} / \mathrm{bh}$ nominal shear stress at $\mathrm{x}=0$ for the rectangular double cantilever beam specimen

stress function

displacement function 


\section{ANALYSIS \\ The Plane Problem (Modes I and II)}

The solution presented in this paper is for a specimen having a zero radius $\mathrm{v}$-notch on one edge. It applies to a homogeneous isotropic material and is in the class of plane elastostatic problems of the theory of linear elasticity.

Plates containing a single edge $\mathrm{v}$-notch are analyzed for symmetric loading (mode I) and antisymmetric loading (mode II). The configurations are shown in figures 2 and 3 ,

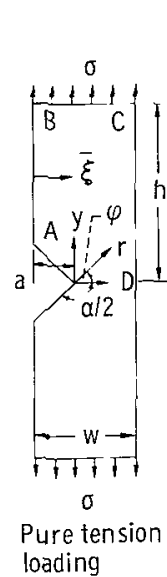
loading

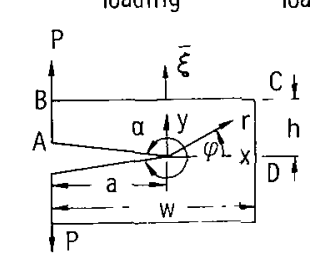

Double cantilever beam specimen.

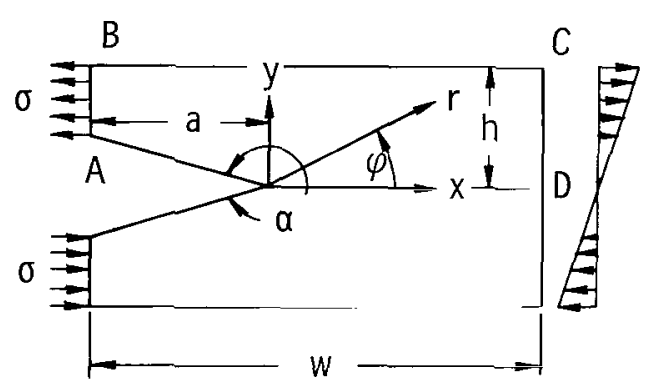

Figure 3. - Single edge notched plate specimen subject to antisymmetric loading (mode II), having a thickness $b$.

Figure 2. - Mode I specimens having a thickness b.

respectively. Stress function solutions are obtained in two parts: the first satisfying the homogeneous (zero) loading or displacement along the notch surfaces and the second satisfying a given load or displacement along the notch surfaces. The most general solution is obtained by a combination of these parts.

We take the origin of coordinates at the tip of the notch as shown in figures 2 and 3 . Neglecting body forces, the differential equations of the system for both plane stress and plane strain reduce to the biharmonic equation 


$$
\nabla^{4} \mathrm{x}=\left(\frac{\partial^{2}}{\partial \mathrm{r}^{2}}+\frac{1}{\mathrm{r}} \frac{\partial}{\partial \mathrm{r}}+\frac{1}{\mathrm{r}^{2}} \frac{\partial^{2}}{\partial \varphi^{2}}\right)\left(\frac{\partial^{2} \mathrm{x}}{\partial \mathrm{r}^{2}}+\frac{1}{\mathrm{r}} \frac{\partial \mathrm{x}}{\partial \mathrm{r}}+\frac{1}{\mathrm{r}^{2}} \frac{\partial^{2} \chi}{\partial \varphi^{2}}\right)=0
$$

The components of the stress tensor are

$$
\begin{gathered}
\sigma_{\mathbf{r}}=\frac{1}{\mathrm{r}^{2}} \frac{\partial^{2} \mathrm{x}}{\partial \varphi^{2}}+\frac{1}{\mathrm{r}} \frac{\partial \mathrm{x}}{\partial \mathrm{r}} \\
\sigma_{\varphi}=\frac{\partial^{2} \mathrm{x}}{\partial \mathrm{r}^{2}} \\
\tau_{\mathbf{r} \varphi}=-\frac{1}{\mathbf{r}} \frac{\partial^{2} \mathrm{x}}{\partial \mathbf{r} \partial \varphi}+\frac{1}{\mathbf{r}^{2}} \frac{\partial \mathrm{x}}{\partial \varphi}
\end{gathered}
$$

It is convenient to define a displacement function $\psi(\mathrm{r}, \varphi)$ such that

$$
\nabla^{2} \mathrm{x}=\frac{\partial^{2}(\mathrm{r} \psi)}{\partial \mathrm{r} \partial \varphi}
$$

Then the displacements can be written (ref. 7)

$$
\left.\begin{array}{c}
2 \mathrm{Gu}_{\mathrm{r}}=-\frac{\partial \mathrm{x}}{\partial \mathrm{r}}+(1-\kappa) \mathrm{r} \frac{\partial \psi}{\partial \varphi} \\
2 \mathrm{Gu}_{\varphi}=-\frac{1}{\mathrm{r}} \frac{\partial \mathrm{X}}{\partial \varphi}+(1-\kappa) \mathrm{r}^{2} \frac{\partial \psi}{\partial \mathrm{r}}
\end{array}\right\}
$$

Assume a stress function $x$ to be given by

$$
\chi(r, \varphi, \lambda)=R_{e}\left[x_{I}(r, \varphi, \lambda)+\chi_{I I}(r, \varphi)\right]
$$

where $R_{e}$ denotes the real part of the bracketed expression, and

$$
\mathrm{X}_{\mathrm{I}}(\mathrm{r}, \varphi, \lambda)=\mathrm{r}^{\lambda} \mathrm{F}(\lambda, \varphi)
$$


where

$$
\mathrm{F}(\lambda, \varphi)=\left[\mathrm{a}_{1} \cos \lambda \varphi+\mathrm{a}_{2} \cos (\lambda-2) \varphi+\mathrm{a}_{3} \sin \lambda \varphi+\mathrm{a}_{4} \sin (\lambda-2) \varphi\right]
$$

and where $\chi_{I}$ satisfies identically the conditions of zero notch surface boundary loads with $\lambda, a_{1}, a_{2}, a_{3}$, and $a_{4}$ being complex numbers and $\chi_{\pi}(r, \varphi)$ represents a function determined from the given nonzero boundary load conditions, if any, along the notch surfaces.

Assume the displacement function $\psi$ to be

$$
\psi(\mathrm{r}, \varphi, \mathrm{m})=\mathrm{R}_{\mathrm{e}}\left[\psi_{\mathrm{I}}(\mathrm{r}, \varphi, \mathrm{m})+\psi_{\mathrm{II}}(\mathrm{r}, \varphi)\right]
$$

where

$$
\psi_{\mathrm{I}}(\mathrm{r}, \varphi, \mathrm{m})=\mathrm{r}^{\mathrm{m}}\left(\mathrm{d}_{1} \cos \mathrm{m} \varphi+\mathrm{d}_{2} \sin \mathrm{m} \varphi\right)=\mathrm{r}^{\mathrm{m}} \mathrm{g}(\varphi, \mathrm{m})
$$

and $\mathrm{m}, \mathrm{d}_{1}$, and $\mathrm{d}_{2}$ may be complex numbers.

Since $x_{I}$ is independent of $x_{I I}$ and $\psi_{I}$ is independent of $\psi_{\text {II }}$ it follows from equation (3) that

$$
\mathrm{m}=\lambda-2 \text { and }(\lambda-1) \frac{\partial \mathrm{g}}{\partial \varphi}=\lambda^{2} \mathrm{~F}+\frac{\partial^{2} \mathrm{~F}}{\partial \varphi^{2}}
$$

and

$$
\nabla^{2} \chi_{\mathrm{II}}=r \frac{\partial^{2} \psi_{\mathrm{II}}}{\partial \mathrm{r} \partial \varphi}+\frac{\partial \psi_{\mathrm{II}}}{\partial \varphi}
$$

From equation (9) we obtain the relation

and

$$
\left.\begin{array}{l}
d_{1}=\frac{-4 a_{4}}{(\lambda-2)} \\
d_{2}=\frac{4 a_{2}}{(\lambda-2)}
\end{array}\right\}
$$


and it follows that

$$
\psi(r, \varphi, \lambda)=R_{e}\left\{\frac{4 r^{\lambda-2}}{(\lambda-2)}\left[-a_{4} \cos (\lambda-2) \varphi+a_{2} \sin (\lambda-2) \varphi\right]+\psi_{I I}\right\}
$$

The homogeneous boundary conditions to be satisfied by the stress function $\chi_{\mathrm{I}}$ are

$$
\tau_{\mathrm{r} \varphi_{\mathrm{I}}}\left(\mathrm{r}, \frac{\alpha}{2}\right)=\tau_{\mathrm{r} \varphi_{\mathrm{I}}}\left(\mathrm{r},-\frac{\alpha}{2}\right)=0
$$

and

$$
\sigma_{\varphi_{\mathrm{I}}}\left(\mathrm{r}, \frac{\alpha}{2}\right)=\sigma_{\varphi_{\mathrm{I}}}\left(\mathrm{r},-\frac{\alpha}{2}\right)=0
$$

From equations (2) and (6) we obtain

$$
\tau_{r \varphi_{\mathrm{I}}}=\mathrm{R}_{\mathrm{e}}\left[-\mathrm{r}^{\lambda-2}(\lambda-1) \frac{\partial \mathrm{F}}{\partial \varphi}\right]
$$

and

$$
\sigma_{\varphi_{I}}=R_{e}\left[r^{\lambda-2} \lambda(\lambda-1) F\right]
$$

Satisfying the boundary conditions of equation (13), using equations (14) and (15) leads to 


$$
\left[\begin{array}{cc}
\cos \lambda \frac{\alpha}{2} & \cos (\lambda-2) \frac{\alpha}{2} \\
\lambda \sin \lambda \frac{\alpha}{2} & (\lambda-2) \sin (\lambda-2) \frac{\alpha}{2}
\end{array}\right]\left[\begin{array}{l}
\mathrm{A}_{1} \\
\mathrm{~A}_{2}
\end{array}\right]=\left[\begin{array}{l}
0 \\
0
\end{array}\right]
$$

and

$$
\left[\begin{array}{cc}
\sin \lambda \frac{\alpha}{2} & \sin (\lambda-\mathrm{a}) \frac{\alpha}{2} \\
\lambda \cos \lambda \frac{\alpha}{2} & (\lambda-2) \cos (\lambda-2) \frac{\alpha}{2}
\end{array}\right]\left[\begin{array}{l}
\mathrm{A}_{3} \\
\mathrm{~A}_{4}
\end{array}\right]=\left[\begin{array}{l}
0 \\
0
\end{array}\right]
$$

where $A_{i}=2 a_{i}$. The resulting eigenequations are

$$
\sin \left(\lambda_{n}-1\right) \alpha={ }_{ \pm}\left(\lambda_{n}-1\right) \sin \alpha
$$

where

$$
\lambda_{n}=\eta_{n}+i \zeta_{n} \quad n=1,2,3, \ldots, \infty
$$

are the complex eigenvalues.

It also follows from equation (16) that

$$
\begin{aligned}
& \mathrm{A}_{1, \mathrm{n}}=\frac{-\cos \left(\lambda_{\mathrm{n}}-2\right) \frac{\alpha}{2}}{\cos \lambda_{\mathrm{n}} \frac{\alpha}{2}} \mathrm{~A}_{2, \mathrm{n}} \\
& \mathrm{A}_{3, \mathrm{n}}=\frac{-\sin \left(\lambda_{\mathrm{n}}-2\right) \frac{\alpha}{2}}{\sin \lambda_{\mathrm{n}} \frac{\alpha}{2}} \mathrm{~A}_{4, \mathrm{n}}
\end{aligned}
$$

The solution for the infinite number of complex roots of these eigenequations was obtained by the Newton-Raphson technique and are tabulated in table I for $\alpha=300^{\circ}$. 
TABLE I. - EIGENVALUES OBTAINED FROM EQUATION (17) FOR $\alpha=300^{\circ}$

\begin{tabular}{|c|c|c|c|c|c|c|c|c|}
\hline \multicolumn{9}{|c|}{ Eigenvalues $\eta+i \zeta$ for the even stress function } \\
\hline $\mathrm{n}$ & $\eta_{\mathrm{n}}$ & $\zeta_{n}$ & $\mathrm{n}$ & $\eta_{\mathrm{n}}$ & $\zeta_{n}$ & $\mathrm{n}$ & $\eta_{\mathrm{n}}$ & $\zeta_{n}$ \\
\hline 1 & 1. 5122214 & 0 & 2 & 2.4710279 & 0.1418529 & 3 & 3.6776151 & 0.2849014 \\
\hline 4 & 4.8814875 & .3604963 & 5 & 6.0840842 & .4136445 & 6 & 7.2859663 & 4548960 \\
\hline 7 & 8.4874029 & 4886817 & 8 & 9.6885409 & .5173204 & 9 & 10.8894680 & 5421866 \\
\hline 10 & 12.0902400 & .5641655 & 11 & 13.2908942 & .5838618 & 12 & 14.4914565 & .6017071 \\
\hline 13 & 15.6919459 & .6180209 & 14 & 16.8923762 & .6330462 & 15 & 18.0927579 & .6469723 \\
\hline 16 & 19.2930992 & .6599493 & 17 & 20.4934061 & .6720988 & 18 & 21.6936841 & .6835201 \\
\hline 19 & 22.8939369 & 6942958 & 20 & 24.0941684 & .7044951 & 21 & 25.2943809 & .7141765 \\
\hline 22 & 26.4945767 & .7233902 & 23 & 27.6947579 & .7321794 & 24 & 28.8949263 & .7405815 \\
\hline 25 & 30.0950830 & .7486291 & 26 & 31.2952292 & .7563511 & 27 & 32.4953661 & .7637728 \\
\hline 28 & 33.6954947 & .7709166 & 29 & 34.8956156 & .7778027 & 30 & 37.2958369 & .7908716 \\
\hline 31 & 37.2958369 & .7908716 & 32 & 38.4959383 & .7970851 & 33 & 39.6960349 & 8031028 \\
\hline 34 & 40.8961263 & 8089365 & 35 & 42.0962129 & .8145973 & 36 & 43.2962956 & 8200950 \\
\hline 37 & 44.4963746 & .8254388 & 38 & 45.6964498 & 8306372 & 39 & 46. 8965216 & 8356977 \\
\hline 40 & 48.0965900 & .8406276 & 41 & 49.2966561 & .8454334 & 42 & 50.4967189 & 8501212 \\
\hline
\end{tabular}

Tables for other values of $\alpha$ are given in reference 19 .

The stress function $X$ can be written separating the even functions and the odd functions as follows:

$$
\chi_{\mathrm{I}}(\mathrm{r}, \varphi, \lambda)=\chi_{\mathrm{IEVEN}}+\chi_{\mathrm{IODD}}
$$

where

$$
\mathrm{X}_{\mathrm{IEVEN}}=\sum_{\mathrm{n}=1}^{\infty} \mathrm{r}^{\lambda} \mathrm{n}\left[\mathrm{A}_{1, \mathrm{n}} \cos \lambda_{\mathrm{n}} \varphi+\mathrm{A}_{2, \mathrm{n}} \cos \left(\lambda_{\mathrm{n}}-2\right) \varphi\right]
$$

and

$$
\left.\mathrm{X}_{\mathrm{IODD}}=\sum_{\mathrm{n}=1}^{\infty} \mathrm{r}^{\lambda}\left[\mathrm{A}_{3, \mathrm{n}} \sin \lambda_{\mathrm{n}} \varphi+\mathrm{A}_{4, \mathrm{n}} \sin \left(\lambda_{\mathrm{n}}-2\right) \varphi\right]\right]
$$

Similarly equation (8) is written as

$$
\psi_{\mathrm{I}}=\psi_{\mathrm{IEVEN}}+\psi_{\mathrm{IODD}}
$$


where

$$
\left.\psi_{\text {IEVEN }}=-4 \sum_{n=1}^{\infty} A_{4, n} \frac{r^{\lambda_{n}-2}}{\left(\lambda_{n}-2\right)} \cos \left(\lambda_{n}-2\right) \varphi\right)
$$

and

Since the stresses and displacements are real, they are associated with the real parts of the stress function $X_{I}$ and displacement function $\psi_{\mathrm{I}}$.

The mode $I$ and $I I$ stress and displacement fields are associated with the even and odd solutions, respectively. The corresponding stress intensity factors $\mathrm{K}_{\mathrm{I}}$ and $\mathrm{K}_{\Pi \mathrm{I}}$ are obtained as follows:

$$
\left.\begin{array}{c}
\mathrm{K}_{\mathrm{I}}=\sqrt{2 \pi} \lim _{\mathrm{r} \rightarrow 0} \mathrm{r}^{2-\eta_{1}}{ }_{\sigma_{\varphi}(\mathrm{r}, 0)} \\
\mathrm{K}_{\mathrm{II}}=\sqrt{2 \pi} \lim _{\mathrm{r} \rightarrow 0} \mathrm{r}^{2-\eta_{1}}\left|\tau_{\mathrm{r}} \varphi(\mathrm{r}, 0)\right|
\end{array}\right\}
$$

The stress intensity factors are thus defined to cancel the singularity. As originally used by Irwin (ref. 21), the stress intensity factor $\mathrm{K}$ is always associated with a zero notch angle (crack). This leads to a square root singularity, that is, $\eta_{1}=3 / 2$. When the notch angle is no longer zero (crack) but less than $180^{\circ}$, the singularity occurring at the notch tip is less than $1 / 2\left(\eta_{1}>3 / 2\right.$, as shown in table VIII).

Hence 


$$
\left.\begin{array}{c}
\mathrm{K}_{\mathrm{I}}=\sqrt{2 \pi} \eta_{1}\left(\eta_{1}-1\right)\left[-\left(\cos \alpha+\frac{\sin \eta_{1} \alpha \sin \alpha}{1+\cos \eta_{1} \alpha}\right)+1\right] \mathrm{R}_{\mathrm{e}} \mathrm{A}_{2,1} \\
\mathrm{~K}_{\mathrm{II}}=\sqrt{2 \pi}\left|\left(\eta_{1}-1\right)\left[\left(\eta_{1}-2\right)+\eta_{1}\left(\frac{\sin \eta_{1} \alpha \sin \alpha}{1-\cos \eta_{1} \alpha}-\cos \alpha\right)\right] \mathrm{R}_{\mathrm{e}} \mathrm{A}_{4,1}\right|
\end{array}\right\}
$$

where $\eta_{1}$ is the real part of $\lambda_{1}$.

The stress function $x_{\Pi}$ is now obtained satisfying $\nabla^{4} x_{I I}=0$ and the appropriate nonzero notch surface boundary load conditions. For example, if

$$
\begin{gathered}
\sigma_{\varphi \mathrm{II}}\left(\mathrm{r}, \frac{\alpha}{2}\right)=\mathrm{k}_{1} \\
\sigma_{\varphi \mathrm{II}}\left(\mathrm{r},-\frac{\alpha}{2}\right)=\mathrm{k}_{2} \\
\tau_{\mathrm{r} \varphi \mathrm{II}}\left(\mathrm{r}, \frac{\alpha}{2}\right)=\mathrm{k}_{3} \\
\tau_{\mathrm{r} \varphi \mathrm{II}}\left(\mathrm{r},-\frac{\alpha}{2}\right)=\mathrm{k}_{4}
\end{gathered}
$$

where $\mathrm{k}_{1}, \mathrm{k}_{2}, \mathrm{k}_{3}$, and $\mathrm{k}_{4}$ are constants, we can choose the stress function $x_{\Pi}$ to be

$$
\mathrm{X}_{\mathrm{II}}=\mathrm{r}^{2}\left(\mathrm{~A}_{\mathrm{II}}+\mathrm{B}_{\mathrm{II}} \sin 2 \varphi+\mathrm{C}_{\mathrm{II}} \cos 2 \varphi+\mathrm{D}_{\mathrm{II}} \varphi\right)
$$

And solving for $A_{\Pi I}, B_{I I}, C_{\Pi I}$, and $D_{I I}$ in order to satisfy equation (22) the stress function $x_{I I}$ is determined, and $X=X_{I}+X_{I I}$ satisfies all the field equations and boundary conditions.

It follows from equation (3) and (7) that the displacement function $\psi_{\text {II }}$ must be such that

$$
\psi_{\Pi}=4 A_{\Pi}{ }^{\varphi+2 D_{\Pi} \varphi^{2}}
$$

For the limiting case of a crack $\left(\alpha=360^{\circ}\right)$, the previous equations reduce to those obtained in reference 7 . 


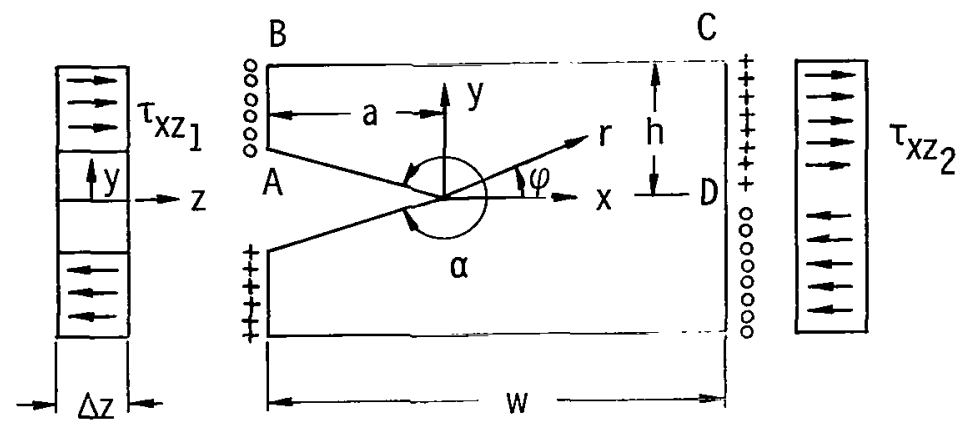

Figure 4. - Single edge notched plate subjected to longitudinal shear (mode III).

\section{THE LONGITUDINAL SHEAR PROBLEM (MODE III)}

For the longitudinal shear problem shown in figure 4 , the in plane displacements $u_{r}$ and $\mathrm{u}_{\varphi}$ are assumed to be zero and the longitudinal displacements $\mathrm{u}_{\mathrm{z}}$ is a function of $\mathrm{x}, \mathrm{y}$. The notch surfaces are thus constrained to a skew symmetric displacement with the surfaces moving parallel to one another. This type of specimen is assumed to be very thick so that all planes far enough removed from the free surfaces behave in the same way. Superposition of the results of this mode III of loading with that of modes I and $\Pi$ is sufficient to describe the most general case of loading on a specimen having a $v$-notch on one edge.

Introducing a stress function $x$ such that

$$
r \tau_{\mathrm{rz}}=-\frac{\partial \mathrm{x}}{\partial \varphi} \quad \text { and } \quad \tau_{\varphi \mathrm{z}}=\frac{\partial \mathrm{x}}{\partial \mathrm{r}}
$$

the equilibrium equations are identically satisfied and the compatibility equation becomes

$$
\frac{1}{\mathrm{r}} \frac{\partial^{2} \chi}{\partial \varphi^{2}}+\frac{\partial x}{\partial \mathrm{r}}+\mathrm{r} \frac{\partial^{2} \chi}{\partial \mathrm{r}^{2}}=\nabla^{2} \mathrm{x}=0
$$

Equation (23) can be solved by the standard technique of separation of variables, resulting in

$$
x=r^{\lambda}\left(B_{1} \cos \lambda \varphi+B_{2} \sin \lambda \varphi\right)
$$


From the boundary conditions along the unloaded notch surfaces, that is,

$$
\tau_{\varphi \mathrm{Z}}=\frac{\partial \mathrm{X}}{\partial \mathrm{r}}=0, \varphi= \pm \frac{\alpha}{2}
$$

and the fact that $\chi$ must be an even function of $\varphi$, it follows that

$$
\cos \frac{\lambda \alpha}{2}=0, \lambda_{\mathrm{m}}=(2 \mathrm{~m}-1) \frac{\pi}{\alpha}
$$

Hence

$$
\mathrm{x}=\sum_{\mathrm{m}=1}^{\infty} \mathrm{r}^{(2 \mathrm{~m}-1) \pi / \alpha} \mathrm{B}_{2 \mathrm{~m}-1} \cos (2 \mathrm{~m}-1) \frac{\pi \varphi}{\alpha}
$$

where values of $\mathrm{m}<1$ have been excluded in order that the displacements remain finite. While the above solution treats the notch surface as being free (i.e., $x=x_{1}$ ), the problem of having known shear stresses along the notch surface may be analyzed as well. The stress function $x$ is considered to be a combination of two functions $x=x_{I}+x_{I I}$ where $x_{I}$ satisfies the homogeneous boundary conditions along the notch surface and $x_{\Pi}$ satisfies the boundary load conditions along the notch surface. For example, to obtain the complete stress function solution assuming a constant shear stress $\tau_{\varphi \mathrm{zII}}$ along the notch surface, let

$$
\mathrm{x}_{\mathrm{II}}=\mathrm{C}_{\mathrm{II}} \mathrm{r} \cos \varphi
$$

which satisfies the compatibility equation

$$
\nabla^{2} x_{I I}=0
$$

To determine $\mathrm{C}_{\mathrm{II}}$ we have

$$
\frac{\partial \mathrm{x}_{\mathrm{II}}\left(\mathrm{r}, \frac{\alpha}{2}\right)}{\partial \mathrm{r}}=\mathrm{C}_{\mathrm{II}} \cos \frac{\alpha}{2}=\tau_{\varphi \mathrm{ZI}}
$$


thus

$$
\mathrm{C}_{\Pi I}=\frac{\tau_{\varphi \mathrm{z} \Pi}}{\cos \frac{\alpha}{2}}
$$

and $x=x_{I}+x_{\Pi}$ satisfies all the required field equations and boundary conditions.

\section{BOUNDARY COLLOCATION SOLUTION}

The previous solutions satisfy exactly the boundary conditions along the notch surfaces. To satisfy the boundary conditions along the rest of the boundary, one must find appropriate values for the unknown coefficients appearing in the series obtained. This can be done by truncating the series as expressed in equation (18) and determining the unknown constants such that the stress function and stress function derivative satisfy the boundary conditions at a finite number $\mathrm{m}$, of selected boundary stations. In doing this, a set of $2 \mathrm{~m}$ simultaneous algebraic equations is obtained and the first $2 \mathrm{~m}$ coefficients of the stress function series are determined. The truncated stress function series thus obtained is considered to be an accurate representation of the actual stress function when further increase in the number of boundary stations produce no significant change in the first coefficient of the stress function series which represents the dominant term in the vicinity of the crack tip. This boundary collocation technique is described in detail in references 3,8 to 12 , and 19 .

For included vertex angles $\alpha$ above $300^{\circ}$, the above method worked very well. However, as $\alpha$ is decreased below $300^{\circ}$ the first coefficient of the stress function oscillated about some value, bracketing this value without actually converging. This difficulty was overcome in a manner similar to that used by Hulbert (ref. 22). More boundary stations were chosen than unknown coefficients leading to an overdetermined system, and the resulting set of simultaneous equations was satisfied in the least squares sense. All the results reported herein are based on the solution to such overdetermined systems. For included angles greater than $300^{\circ}$ the results of overdetermined systems were the same as for the ordinary system consisting of an equal number of equations and unknowns. Those early results referred to in references 3 , and 8 to 12 did not use overdetermined systems as this was unnecessary. In solving the resulting set of $n$ simultaneous equations in $n$ unknowns, a Gauss-Jordon pivotal condensation routine was used.

Since the most important quantity to be determined is the stress intensity factor $\mathrm{K}$, preliminary trials were made to determine the number of equations necessary for evaluating $\mathrm{K}$ with sufficient accuracy for the case of pure tension, pure bending, and three- 
TABLE II. - DIMENSIONLESS STRESS INTENSITY

FACTORS FOR SINGLE-EDGE NOTCHED SPECIMEN

\begin{tabular}{|c|c|c|c|c|c|c|}
\hline \multirow{2}{*}{$\begin{array}{c}\text { Included } \\
\text { vertex, } \\
\text { angle. } \\
\alpha, \\
\text { deg }\end{array}$} & \multicolumn{6}{|c|}{ Notch length to plate width ratio, $a / w$} \\
\hline & 0.2 & 0.3 & 0.4 & 0.5 & 0.6 & 0.7 \\
\hline & \multicolumn{6}{|c|}{ Pure tension; 1} \\
\hline 360 & 1.085 & 1.614 & 2.369 & 3.539 & 5.537 & 9.422 \\
\hline 350 & 1.085 & 1.613 & 2.369 & 3.541 & 5.538 & 9.426 \\
\hline 340 & 1.087 & 1.618 & 2.374 & 3.549 & 5.549 & 9.445 \\
\hline 330 & 1.097 & 1.630 & 2.389 & 3.569 & 5.579 & 9.491 \\
\hline 300 & 1.169 & 1.724 & 2.520 & 3.756 & 5.859 & 9.979 \\
\hline 270 & 1. 366 & 1.987 & 2.888 & 4.297 & 6.736 & 11.515 \\
\hline 240 & 1.804 & 2.595 & 3.766 & 5.630 & 8.934 & 15.551 \\
\hline & \multicolumn{6}{|c|}{ Pure bending; $\mathrm{K}_{\mathrm{I}} \mathrm{bw}^{\eta_{1}-1}$} \\
\hline & \multicolumn{6}{|c|}{$6 \mathrm{M}$} \\
\hline 360 & 0.837 & 1.093 & 1.414 & 1.877 & 2.629 & 4.041 \\
\hline 350 & .836 & 1.093 & 1.414 & 1.876 & 2.627 & 4.044 \\
\hline 340 & .839 & 1.095 & 1.416 & 1.878 & 2.632 & 4.048 \\
\hline 330 & .844 & 1.100 & 1.422 & 1.885 & 2.640 & 4.062 \\
\hline 300 & .895 & 1.155 & 1.484 & 1.965 & 2.752 & 4.250 \\
\hline 270 & 1.034 & 1. 314 & 1.678 & 2.218 & 3.139 & 4.873 \\
\hline \multirow[t]{3}{*}{240} & 1. 346 & 1.680 & 2.146 & 2.860 & 4.112 & 6.532 \\
\hline & \multicolumn{6}{|c|}{$\mathrm{K}_{\mathrm{I}} \mathrm{bw}^{\eta{ }_{1}-1}$} \\
\hline & \multicolumn{3}{|c|}{ Three-point loading; } & $6 \mathrm{~F}$ & & \\
\hline 360 & 0.777 & 1.013 & 1. 318 & 1.767 & 2.504 & 3.893 \\
\hline 350 & .776 & 1.012 & 1. 319 & 1.766 & 2.504 & 3.898 \\
\hline 340 & .779 & 1.014 & 1. 320 & 1.767 & 2.505 & 3.903 \\
\hline 330 & .785 & 1.021 & 1. 325 & 1.775 & 2.517 & 3.922 \\
\hline 300 & .832 & 1.072 & 1. 390 & 1.857 & 2.636 & 4. 112 \\
\hline 270 & .963 & 1.226 & 1.578 & 2.118 & 3.012 & 4. 736 \\
\hline 240 & 1.261 & 1.573 & 2.043 & 2.770 & 3.984 & 6.395 \\
\hline
\end{tabular}


TABLE III. - DIMENSIONLESS STRESS INTENSITY FACTORS FOR AN EDGE-NOTCHED RECTANGULAR DOUBLE-CANTILEVER BEAM

SUBJECT TO SPLITTING FORCES

\begin{tabular}{|c|c|c|c|c|c|c|c|c|}
\hline \multirow{3}{*}{$\begin{array}{l}\text { Included } \\
\text { vertex } \\
\text { angle, } \\
\alpha, \\
\text { deg }\end{array}$} & \multirow{3}{*}{$\begin{array}{l}\text { Maximum beam } \\
\text { depth to notch } \\
\text { depth ratio, } \\
\text { h/a }\end{array}$} & \multicolumn{7}{|c|}{ Notch depth to plate width ratio, a/w } \\
\hline & & 0.667 & 0.500 & 0.400 & 0.333 & 0.250 & 0.222 & 0.200 \\
\hline & & \multicolumn{7}{|c|}{$\mathrm{Pa}^{2-\eta_{1}}$} \\
\hline \multirow[t]{4}{*}{360} & 0.5 & 8. 320 & 6.565 & ---- & 6.560 & 6.485 & $---\infty$ & 6.587 \\
\hline & 1.0 & 14.829 & 7.202 & ---- & 5.810 & 5. 798 & ----- & 5.798 \\
\hline & 1.5 & 22.209 & 9.896 & ---- & 6.033 & 5.695 & ---- & 5.678 \\
\hline & 2.0 & 29.623 & 13.039 & ---- & 6.958 & 5. 913 & ---- & 5.730 \\
\hline \multirow[t]{4}{*}{350} & 0.5 & 8. 344 & 6.601 & $-\ldots-$ & 6.571 & 6.593 & ---- & 6.606 \\
\hline & 1. 0 & 14.837 & 7.211 & ---- & 5.822 & 5.815 & $-\ldots$ & 5.810 \\
\hline & 1.5 & 22.213 & 9.899 & $-\ldots-$ & 6.033 & 5.699 & ---- & 5.709 \\
\hline & 2.0 & 29.630 & 13.038 & $\ldots$ & 6.952 & 5.910 & ---- & 5.752 \\
\hline \multirow[t]{4}{*}{340} & 0.5 & 8. 360 & 6.619 & $-\ldots$ & 6.634 & 6.611 & 6.732 & --- \\
\hline & 1.0 & 14.853 & 7.215 & ----- & 5.830 & 5. 812 & 5.810 & ---- \\
\hline & 1.5 & 22.240 & 9.903 & $\ldots$ & 6.035 & 5.696 & 5.678 & ---- \\
\hline & 2.0 & 29.589 & 13.048 & ---- & 6.950 & 5.906 & 5.789 & $\ldots$ \\
\hline \multirow[t]{4}{*}{330} & 0.5 & 8. 383 & 6.639 & $-\cdots--$ & 6.636 & 6.641 & -.-- & $\ldots$ \\
\hline & 1.0 & 14.904 & 7.230 & ---- & 5.835 & 5.822 & 5.822 & 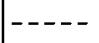 \\
\hline & 1.5 & 22.320 & 9.928 & ---- & 6.040 & 5.705 & 5.689 & ---- \\
\hline & 2.0 & 29.775 & 13.085 & $\ldots-$. & 6.956 & 5.904 & 5.787 & $-\cdots$ \\
\hline \multirow[t]{3}{*}{300} & 1.0 & 15.509 & 7.426 & $-\ldots-$ & 5.964 & 5.947 & $-\ldots$ & 5.961 \\
\hline & 1.5 & 23.263 & 10.253 & $-\cdots$ & 6.168 & 5.781 & 5.767 & $-\cdots$ \\
\hline & 2.0 & 31.040 & 13.541 & ----- & 7.122 & 6.071 & 5.881 & $-\ldots$ \\
\hline \multirow[t]{2}{*}{270} & 1.5 & 26.333 & 11.300 & 7. 741 & 6.509 & 6.707 & ---- & ---- \\
\hline & 2.0 & 35.139 & 14.985 & 9. 732 & 7.654 & 6.307 & ---- & $\mid---$ \\
\hline
\end{tabular}


point loading. Over the range of geometries analyzed it was indicated that an overdetermined system of 52 equations and 40 unknowns were sufficient. For the double cantilever beam antisymmetrically loaded, it was found that a set of 64 equations and 40 unknowns were sufficient.

\section{Numerical Results}

Calculations were performed for mode I notch opening for the cases of pure tension, pure bending, three-point loading, and the double cantilever beam subjected to splitting forces as shown in figure 2. Calculations were also performed for the antisymmetric mode $\Pi$ notch opening as shown in figure 3 . The required boundary conditions for all these cases are given in the appendix.

Preliminary results indicated that for pure tension, pure bending, and three-point loading, increasing the height to width ratio $\mathrm{h} / \mathrm{w}$ beyond 1.2 (fig. 1) for $\alpha>300^{\circ}$ and beyond 1.4 for $300^{\circ}>\alpha \geq 240^{\circ}$ produced no change in the stress intensity factor. These $\mathrm{h} / \mathrm{w}$ values were therefore used in all the subsequent calculations.

The values of the computed stress intensity factors $K_{I}$ and $K_{I}$ are given in tables $\Pi$ to IV for various values of notch angle $\alpha$ and notch depth ratios a/w. For the

TABLE IV. - DIMENSIONLESS STRESS INTENSITY FACTORS

FOR SINGLE-EDGE NOTCHED SPECIMEN SUBJECTED TO

ANTISYMMETRIC LOADING, MODE II

\begin{tabular}{|c|c|c|c|c|c|}
\hline \multirow{4}{*}{$\begin{array}{c}\text { Included } \\
\text { vertex } \\
\text { angle, } \\
\alpha, \\
\text { deg } \\
\\
360\end{array}$} & \multirow{3}{*}{$\begin{array}{l}\text { Maximum beam } \\
\text { depth to notch } \\
\text { depth ratio, } \\
\text { h/a }\end{array}$} & \multicolumn{4}{|c|}{ Notch depth to plate width ratio, a/w } \\
\hline & & 0.400 & 0.333 & 0.286 & 0.200 \\
\hline & & \multicolumn{4}{|c|}{$\frac{\mathrm{K}_{\mathrm{II}}^{\mathrm{bh}}}{\mathrm{Pa}^{2-\eta_{1}}}$} \\
\hline & $\begin{array}{l}0.5 \\
1.0 \\
1.5\end{array}$ & $\begin{array}{r}0.353 \\
.500 \\
.614\end{array}$ & $\begin{array}{r}0.353 \\
.500 \\
.612\end{array}$ & $\begin{array}{r}0.353 \\
.500 \\
.612\end{array}$ & $\begin{array}{r}0.352 \\
.500 \\
.612\end{array}$ \\
\hline 350 & $\begin{array}{l}0.5 \\
1.0 \\
1.5\end{array}$ & $\begin{array}{r}0.186 \\
.401 \\
.543\end{array}$ & $\begin{array}{r}0.186 \\
.401 \\
.540\end{array}$ & $\begin{array}{r}0.186 \\
.401 \\
.540\end{array}$ & $\begin{array}{l}--\cdots- \\
-\cdots-- \\
-----\end{array}$ \\
\hline 340 & $\begin{array}{l}1.0 \\
1.5\end{array}$ & $\begin{array}{r}0.278 \\
.456\end{array}$ & $\begin{array}{r}0.278 \\
.454\end{array}$ & $\begin{array}{r}0.278 \\
.454\end{array}$ & ---- \\
\hline 330 & $\begin{array}{l}1.0 \\
1.5\end{array}$ & $\begin{array}{r}0.124 \\
.348\end{array}$ & $\begin{array}{r}0.124 \\
.346\end{array}$ & $\begin{array}{r}0.124 \\
.346\end{array}$ & $\begin{array}{l}----- \\
-----\end{array}$ \\
\hline
\end{tabular}


double cantilever beam, the beam depth to notch depth ratio $h / a$ was also varied as shown in table III.

Typically computed equivalent stress contours and notch displacement values for the case of three-point loading are shown in figures 5 and 6 . Tables and figures are given in reference 20 , covering a much wider range of geometries and loading.
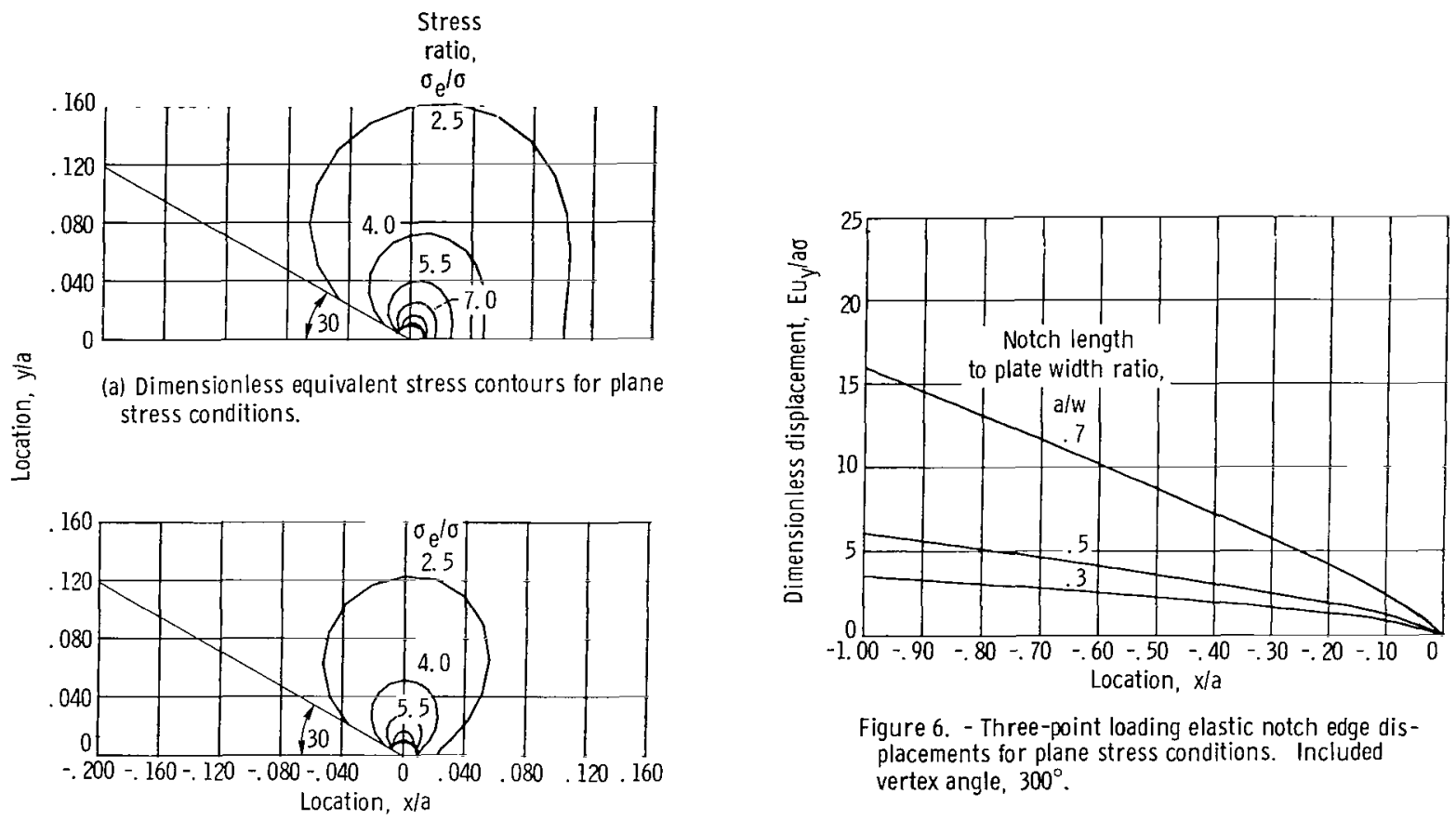

Figure 6. - Three-point loading elastic notch edge displacements for plane stress conditions. Included vertex angle, $300^{\circ}$

(b) Dimensionless equivalent stress contours for plane strain conditions.

Figure 5. - Edge notched beam subjected to three point loading. Included vertex angle, $300^{\circ}$; Poissons ratio, 0.30 ; notch length to plate width ratio, $0.50 ; \sigma=6 \mathrm{P} / \mathrm{bw}$.

\section{EXPERIMENTAL MEASUREMENT OF DISPLACEMENT}

For comparison with the analytical results, crack surface displacement measurements were made on several $\mathrm{v}$-notched plate specimens of 7075T651 bare aluminum, which were subjected to three-point bending. Measurement points were symmetrically located on opposite sides of the edges of the v-notch. Figures 7 to 9 shows the equipment used. Numbers appearing in figures 8 and 9 refer to the various components indicated in figure 7 . The bend specimens were 9 -inches long by 2 -inches wide by 1 -inch thick with a span length-to-width ratio of 4 to 1 . Nine specimens were tested corresponding to $\alpha$ values of $330^{\circ}, 300^{\circ}$, and $270^{\circ}$, and $a / w$ ratios of $0.4,0.5$, and 0.6 . 


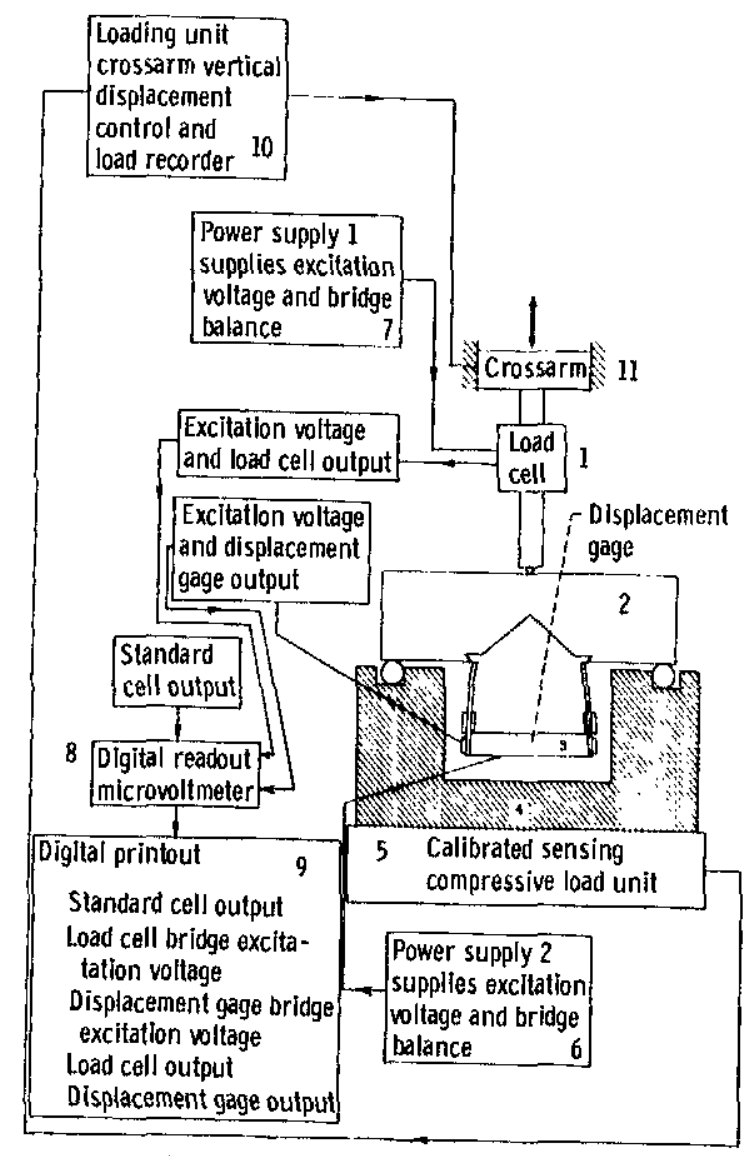

Figure 7. - Schematic of experimental test rig.

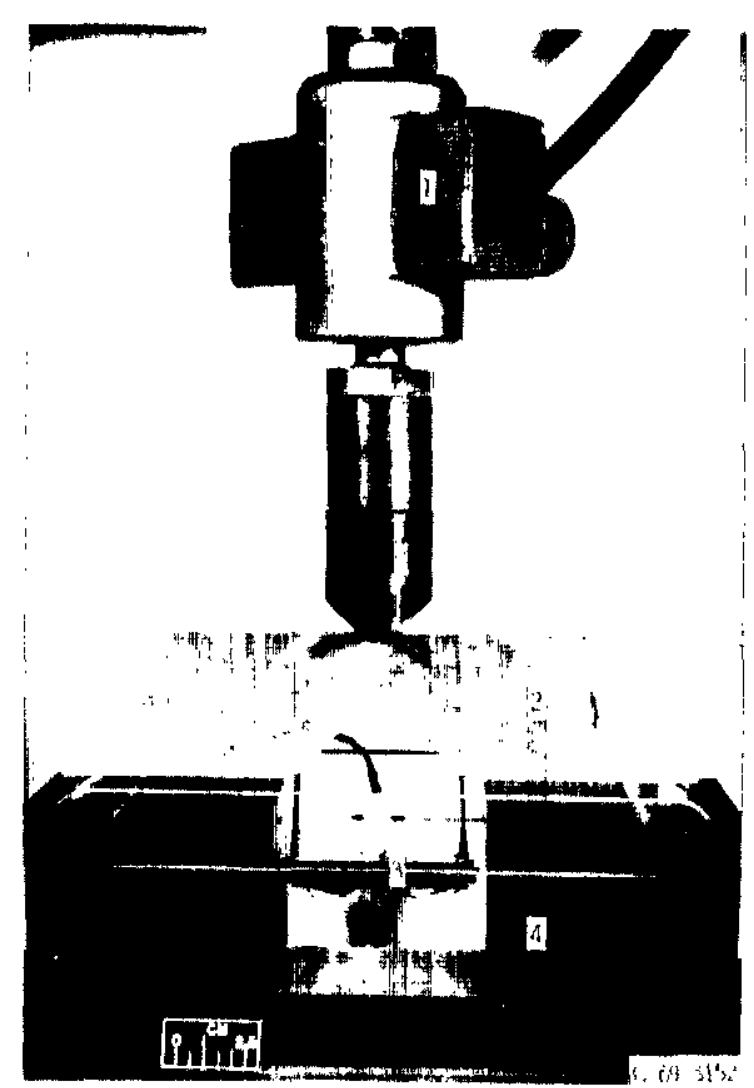

Figure X. - Clase up of loadiny fixlure and instrumented sperimen. (Niminters correspond to thuse shitim in fit. 7. .) 


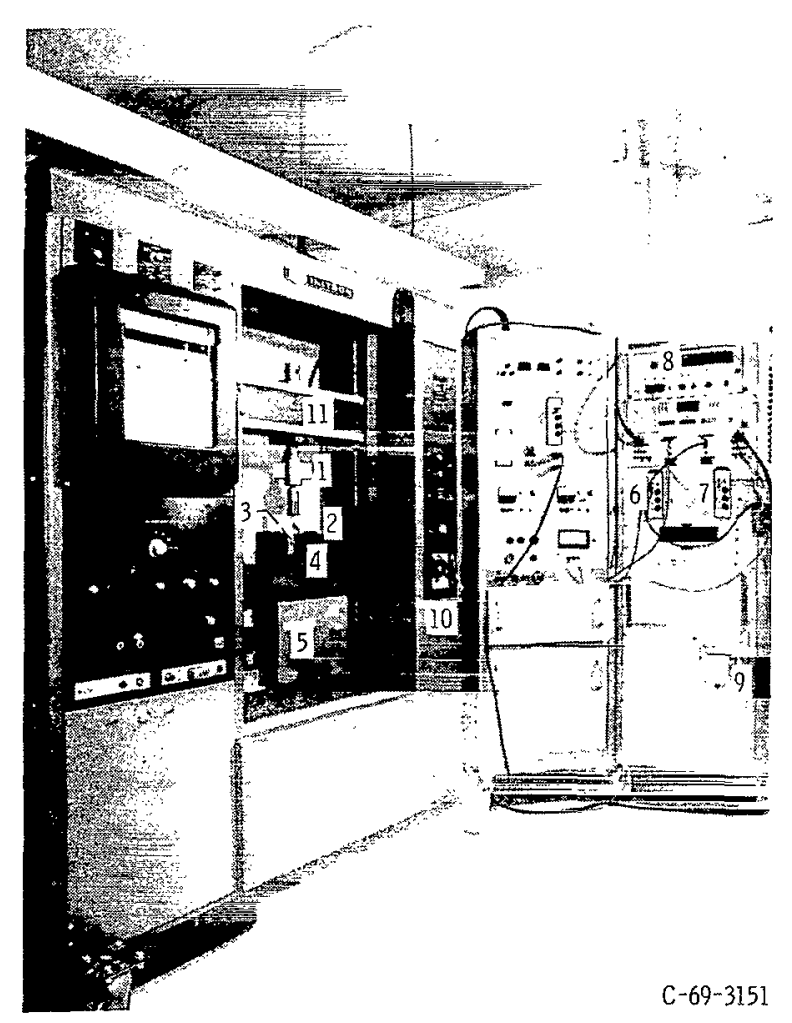

Figure 9. - Loading frame, fixtures, and instrumentation. (Numbers correspond to those in fig.7.)

The modulus of elasticity of the aluminum was taken as $10.4 \times 10^{6}$ psi. The equipment used and the experimental procedures are described in detail in reference 19.

\section{RESULTS AND DISCUSSION}

Results are presented in tables II to $V$. The value of the first term of the truncated even stress function $R_{e}\left(A_{2,1}\right)$ or $R_{e}\left(A_{4,1}\right)$ is directly proportional to the stress intensity factor $\mathrm{K}_{\mathrm{I}}$ or $\mathrm{K}_{\mathrm{II}}$. Tables II to IV contain the nondimensional stress intensity factors for mode I and mode $I$.

For all mode $I$ cases considered the value of $K$ increased a maximum of 1 percent in going from $\alpha=360^{\circ}$ (crack) to $330^{\circ}$. The square root singularity associated with the $360^{\circ}$ crack changed from 0.5000 to 0.4996 in going from $360^{\circ}$ (crack) to $330^{\circ}$. One can conclude on examining the results of table $\mathrm{II}$ that as long as $\alpha$ is $330^{\circ}$ or greater the difference in the stress intensity factor $K_{I}$ from that for a crack is very small. Table IV contains the nondimensional mode $\Pi$ stress intensity factors. Clearly, small changes in $\alpha$ produce large changes in $\mathrm{K}_{\mathrm{II}}$. 
TABLE V. - COMPARISON OF EXPERIMENTALLY

MEASURED AND COMPUTED PLANE STRESS

DIMENSIONLESS DIS PLACEMENT VALUES

FOR THREE-POINT BENDING

[Span to width ratio, 4 to $1 ; \sigma=P /$ bw. ]

\begin{tabular}{|c|c|c|c|c|}
\hline \multirow[t]{2}{*}{$\begin{array}{c}\text { Specimen } \\
\text { number }\end{array}$} & \multirow[t]{2}{*}{$\begin{array}{c}\text { Included } \\
\text { vertex } \\
\text { angle, } \\
\alpha, \\
\text { deg }\end{array}$} & \multirow[t]{2}{*}{$\begin{array}{l}\text { Notch depth } \\
\text { to plate } \\
\text { width ratio, } \\
\text { a/w }\end{array}$} & \multicolumn{2}{|c|}{$\begin{array}{c}\text { Dimensionless } \\
\text { plane-stress } \\
\text { displacements, } \\
2 \mathrm{Eu} \mathrm{u}_{\mathrm{y}} / \mathrm{a} \sigma\end{array}$} \\
\hline & & & Experimental & Computed \\
\hline 1 & 330 & 0.4 & 8.69 & 8.72 \\
\hline 2 & & .5 & 11.86 & 11.89 \\
\hline 3 & & .6 & 17.71 & 17.86 \\
\hline 4 & 300 & 0.4 & 8.90 & 8.92 \\
\hline 5 & & .5 & 12.17 & 12.19 \\
\hline 6 & 1 & .6 & 18.07 & 18.37 \\
\hline 7 & 270 & 0.4 & 9.46 & 9.55 \\
\hline 8 & 1 & 5 & 13.01 & 13.12 \\
\hline 9 & 1 & .6 & 19.80 & 20.00 \\
\hline
\end{tabular}

Figure 5 contains typical closed contour curves of dimensionless equivalent stress. One obtains from these contours a semiqualitative look into possible regions of plastic flow and their shapes. Straight lines have been drawn between points of constant equivalent stress along rays emanating from the crack tip at $10^{\circ}$ intervals.

A typical dimensionless plane stress y displacement curve along the notch surface is plotted in figure 6 for mode I. Displacements were computed along the notch at intervals of one-tenth the relative notch depth $\mathrm{r} / \mathrm{a}$. Corresponding plane strain displacements may be obtained by multiplying the plane stress y displacement by $\left(1-\nu^{2}\right)$.

Confidence in the correctness of the results obtained by the method of the present analysis was derived from many comparisons, both with the experimental results obtained herein as well as experimental results of other authors for the crack $\left(\alpha=360^{\circ}\right.$ ) problem. Additional verification was obtained when comparisons were made with solutions to several special cases by other investigators using different analytical techniques.

Table VI shows a comparison of the dimensionless stress intensity factor obtained by the present method for the cases of pure tension, pure bending, and three-point loading with experimental results (refs. 13 to 15) and analytical results (ref. 18) of other investigators. Good agreement is obtained.

Table VII shows a comparison of the plane stress dimensionless displacement ob- 
TABLE VI. - COMPARISON OF DIMENSIONLESS STRESS INTENSITY FACTORS FOR SPECIMEN

SUBJECTED TO PURE TENSION, PURE BENDING, AND THREE-POINT LOADING

[Vertex angle, $360^{\circ}$; Mode I (see fig. 2).]

\begin{tabular}{|c|c|c|c|c|c|c|c|c|c|c|}
\hline \multirow[t]{2}{*}{ Type of data } & \multirow[t]{2}{*}{ Source } & \multicolumn{9}{|c|}{ Notch depth to plate width ratio, a/w } \\
\hline & & 0.10 & 0.15 & 0.20 & 0.25 & 0.30 & 0.35 & 0.40 & 0.45 & 0.50 \\
\hline \multicolumn{11}{|c|}{ Pure tension; dimensionless stress intensity factor, $\mathrm{K}_{\mathrm{I}}^{2} \mathrm{wb}^{2} / \mathrm{P}^{2}$} \\
\hline Experimental & Ref. 15 & 0.556 & 0.816 & 1. 180 & 1. 735 & 2.571 & 3.775 & 5.436 & 7.641 & 10.477 \\
\hline Experimental & Ref. 13 & .65 & 1.00 & 1.40 & 1.97 & 2.80 & 4.20 & 6.18 & 8.90 & 12.50 \\
\hline Collocation & Ref. 5 & .445 & .758 & 1. 180 & 1. 768 & 2.603 & 3. 813 & 5.596 & 8. 276 & 12.399 \\
\hline Analytical & Ref. 18 & .443 & .747 & 1. 164 & 1. 751 & 2.592 & 3.813 & 5.606 & 8.284 & 12.363 \\
\hline \multicolumn{11}{|c|}{ Pure bending; dimensionless stress intensity factor, $\mathrm{K}_{\mathrm{I}}^{2} \mathrm{~b}^{2} \mathrm{w}^{3} / \mathrm{M}^{2}$; } \\
\hline Collocation & Ref. 8 & 12.4 & 18.5 & 25.3 & 33.2 & 42.8 & 55.2 & 71.4 & 92.7 & 123.0 \\
\hline Experimental & Ref. 14 & 11.8 & 17.4 & 24.2 & 32.15 & 41.9 & 53.9 & 68.6 & 88.9 & 118.0 \\
\hline Analytical & Ref. 18 & 12.37 & 18.28 & 24.94 & 32.95 & 42.85 & 55.57 & 72.14 & 94.5 & 125.5 \\
\hline \multicolumn{11}{|c|}{$\begin{array}{l}\text { Three-point loading; dimensionless stress intensity factor. } \mathrm{K}_{\mathrm{I}}^{2} \mathrm{~b}^{2} \mathrm{w}^{3} / \mathrm{M}^{2} \text {; } \\
\text { span to width ratio, } 4 / 1\end{array}$} \\
\hline Collocation & This work & $\ldots-\ldots$ & $-\ldots$ & 21.78 & $\ldots$ & 36.89 & $\ldots . .$. & 62.50 & $\ldots-\ldots$ & 112.34 \\
\hline Experimental & (a) & $---\ldots$ & ----- & 20.26 & ----- & 37.62 & $-\cdots---$ & 61.75 & ----- & 110.77 \\
\hline
\end{tabular}

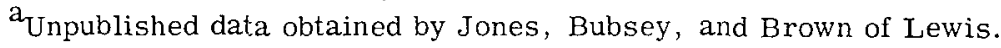

TABLE VII. - COMPARISON OF PLANE-STRESS DIMENSIONLESS DIS PLACEMENT ACROSS NOTCH SURFACES FOR THE THREE-POINT LOADING SPECIMEN AND RECTANGULAR DOUBLE-CANTILEVER BEAM SUBIECT TO SPLITTING FORCES

[Vertex angle, $360^{\circ}$, see fig. 2.]

\begin{tabular}{|c|c|c|c|c|c|c|c|c|c|c|c|}
\hline \multirow[t]{2}{*}{ Type of data } & \multirow[t]{2}{*}{ Source } & \multicolumn{2}{|c|}{ Gage location } & Plate width & \multicolumn{7}{|c|}{ Notch depth to plate width ratio, a/w } \\
\hline & & $\mathrm{x} / \mathrm{w}$ & $y / w$ & $\begin{array}{l}\text { height } \\
\text { ratio. } \\
w / h\end{array}$ & 0.20 & 0.30 & 0.40 & 0.50 & 0.60 & 0.70 & 0.80 \\
\hline \multicolumn{12}{|c|}{ Three-point loading; dimensionless displacement, $2 \mathrm{Ebu}_{\mathrm{y}} \mathrm{w} / 6 \mathrm{M}$} \\
\hline Collocation & This work & $-a / w$ & \pm 0 & $5 / 6$ & 1. 159 & 2.075 & 3.497 & 5.942 & 10.672 & 21.446 & 51.370 \\
\hline Collocation & This work & $-\mathrm{a} / \mathrm{w}$ & \pm .10 & $5 / 6$ & 1. 166 & 2.077 & 3.497 & 5.943 & 10.672 & 21.445 & 51.399 \\
\hline Experimental & (a) & $-\mathbf{a},^{\prime} \mathbf{w}$ & \pm .10 & --- & 1. 176 & 2.124 & 3.556 & 6.032 & 10.29 & 21.09 & 51.53 \\
\hline \multicolumn{12}{|c|}{ Rectangular double-cantilever beam subject to splitting forces: dimensionless displacement. $2 \mathrm{Ebu} \mathrm{y} / \mathrm{P}$} \\
\hline Collocation & This work & $-(\mathrm{a} / \mathrm{w}+1 / 4)$ & \pm 0 & $5 / 3$ & $\cdots--$ & 23.47 & 34.73 & 50.13 & 87.18 & 163.39 & 395.7 \\
\hline Experimental & (a) & $-(a / w+1 / 4)$ & \pm 0 & $5 / 3$ & $\ldots--$ & 24.21 & 35.44 & 53.93 & 88.83 & 161.14 & 380.0 \\
\hline
\end{tabular}

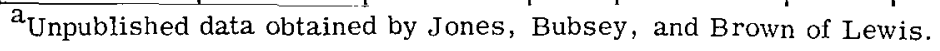


TABLE VIII. - TABLE OF FIRST

EIGENVALUES FOR MODES I

AND II FOR VARIOUS

INCLUDED VERTEX

ANGLES

\begin{tabular}{|c|c|l|}
\hline $\begin{array}{c}\text { Included vertex } \\
\text { angle, } \\
\text { deg }\end{array}$ & \multicolumn{2}{|l|}{ First eigenvalues, $\eta_{1}$} \\
\cline { 2 - 3 } 360 & Mode I & Mode II \\
350 & 1.500000 & 1.500000 \\
340 & 1.500053 & 1.529355 \\
330 & 1.500426 & 1.562007 \\
300 & 1.501453 & 1.598192 \\
270 & 1.512221 &.---- \\
240 & 1.544484 &.---- \\
\hline
\end{tabular}

tained by the technique presented herein with that obtained experimentally (unpublished data obtained by Jones, Bubsey, and Brown of Lewis) for the cases of three-point bending and rectangular double-cantilever beam subject to splitting forces. For the rectangular double-cantilever case the displacements were extrapolated linearly to the specimen edge $[\mathrm{x}=-(\mathrm{a}+\mathrm{w} / 4), \mathrm{y}=0]$. Once again good agreement is obtained. A more detailed comparison of the analytical and experimental results is given in reference 19.

For included vertex angles $\alpha$ less than $360^{\circ}$, no experimental or analytical data have heretofore been available. Experiments, as previously described were therefore made for a three-point bend specimen, and the results were compared with the analysis presented herein for the case of plane stress and are shown in table V. Results are given for $\alpha$ values of $330^{\circ}, 300^{\circ}$, and $270^{\circ}$ and notch depth to plate width ratios $\mathrm{a} / \mathrm{w}$ of $0.4,0.5$, and 0.6 . Excellent agreement is obtained over the range of $a / w$ ratios.

\section{Lewis Research Center,}

National Aeronautics and Space Administration,

Cleveland, Ohio, July 1, 1970 ,

731-25. 


\section{APPENDIX - STRESS FUNCTION AND STRESS FUNCTION DERIVATIVE ALONG THE BOUNDARY OF V-NOTCH SPECIMEN}

For pure tension as shown in figure 2

Along $\mathrm{AB}$

$$
x=0 \quad \frac{\partial x}{\partial x}=0
$$

Along BC

$$
\frac{x}{p}=\frac{1}{b w}\left(\frac{x^{2}}{2}+a x+\frac{a^{2}}{2}\right) \quad \frac{\partial x}{\partial y}=0
$$

Along CD

$$
\frac{\mathrm{x}}{\mathrm{P}}=\frac{\mathrm{w}}{2 \mathrm{~b}} \quad \frac{\mathrm{b}}{\mathrm{P}} \frac{\partial \mathrm{x}}{\partial \mathrm{x}}=1
$$

For pure bending as shown in figure 2

Along $\mathrm{AB}$

$$
x=0 \quad \frac{\partial x}{\partial x}=0
$$

Along BC

$$
\frac{b x}{M}=-\frac{12}{w^{3}}\left(\frac{a^{3}}{6}+\frac{a^{2} x}{2}+\frac{a x^{2}}{2}+\frac{x^{3}}{6}\right)+\frac{6}{w^{2}}\left(\frac{x^{2}}{2}+a x+\frac{a^{2}}{2}\right) \quad \frac{\partial x}{\partial y}=0
$$

Along CD

$$
\frac{b x}{M}=1 \quad \frac{\partial x}{\partial x}=0
$$


For three-point loading as shown in figure 2

Along AB

$$
x=0 \quad \frac{\partial x}{\partial x}=0
$$

Along $\mathrm{BC}$

$$
\begin{gathered}
\frac{x}{P}=\frac{6}{b w}\left(\frac{s}{2}-h\right)\left[-\frac{x^{3}}{6}+\frac{x^{2}}{4}(w-2 a)+\frac{x a}{2}(w-a)+\frac{a^{2}}{2}\left(\frac{w}{2}-\frac{a}{3}\right)\right] \\
\quad \frac{b}{P} \frac{\partial x}{\partial y}=\frac{-6}{3}\left[-\frac{x^{3}}{6}+\frac{x^{2}}{4}(w-2 a)+\frac{x a}{2}(w-a)+\frac{a^{2}}{2}\left(\frac{w}{2}-\frac{a}{3}\right)\right]
\end{gathered}
$$

Along $\mathrm{CC}^{\prime}$

$$
\frac{x}{P}=\frac{s-2 y}{4 b} \quad \frac{\partial x}{\partial x}=0
$$

Along C'D

$$
\frac{x}{P}=\frac{1}{4 b}\left[s-2 y-\frac{\left(y-y_{0}\right)^{2}}{y_{o}}\right] \quad \frac{\partial x}{\partial x}=0
$$

For the rectangular specimen subject to splitting forces as shown in figure 2

\section{Along AB}

$$
\begin{aligned}
\frac{X}{\mathrm{P}} & =\frac{\rho}{\mathrm{b}}\left[\frac{(\gamma+\theta) \sin \gamma \sin \theta+\sin ^{2} \gamma \sin (\gamma+\theta)}{2 \gamma+\sin 2 \gamma}\right. \\
& +(\theta+\gamma) \cos \gamma \cos \theta-\cos ^{2} \gamma \sin (\gamma+\theta) \\
2 \gamma-\sin 2 \gamma & \\
& +\frac{\mathrm{e}}{2 \mathrm{~b}}\left(\frac{\sin 2 \theta-2 \theta \cos 2 \gamma}{2 \gamma \cos 2 \gamma-\sin 2 \gamma}-1\right)
\end{aligned}
$$


where

$$
\begin{gathered}
\gamma=\frac{2 \pi-\alpha}{4} \\
\mathrm{e}=\frac{\mathrm{h}+\mathrm{a} \tan \frac{\alpha}{2}}{\tan 2 \gamma} \\
\rho=\sqrt{(\mathrm{h}-\mathrm{r} \sin \varphi)^{2}+(\mathrm{e}+\mathrm{a}+\mathrm{r} \cos \varphi)^{2}} \\
\theta=\gamma-\tan ^{-1}\left(\frac{\mathrm{h}-\mathrm{r} \sin \varphi}{\mathrm{e}+\mathrm{a}+\mathrm{r} \cos \varphi}\right)
\end{gathered}
$$

and the stress function derivatives is obtained from

$$
\frac{\mathrm{b}}{\mathrm{P}} \frac{\partial \mathrm{x}}{\partial \mathrm{x}}=\frac{\mathrm{b}}{\mathrm{P}} \nabla \mathrm{x} \cdot \bar{\xi}
$$

where $\bar{\xi}$ is a unit vector normal to boundary.

Along $\mathrm{BC}$

$$
\frac{x}{P}=\left(\frac{x+a}{b}\right) \quad \frac{\partial x}{\partial y}=0
$$

Along CD

$$
\frac{\mathrm{x}}{\mathrm{P}}=\frac{\mathrm{w}}{\mathrm{b}} \quad \frac{\mathrm{b}}{\mathrm{P}} \frac{\partial \mathrm{x}}{\partial \mathrm{x}}=1
$$

For the Antisymmetric loading as shown in figure 3

Along $\mathrm{AB}$

$$
\frac{\mathrm{x}}{\mathrm{P}}=\frac{\left(\mathrm{y}+\mathrm{a} \tan \frac{\alpha}{2}\right)^{2}}{2 \mathrm{~b}\left(\mathrm{~h}+\mathrm{a} \tan \frac{\alpha}{2}\right)} \quad \frac{\partial \mathrm{x}}{\partial \mathrm{x}}=0
$$




$$
\frac{\mathrm{X}}{\mathrm{P}}=\frac{\mathrm{h}+\mathrm{a} \tan \frac{\alpha}{2}}{2 \mathrm{~b}} \quad \frac{\mathrm{b}}{\mathrm{P}} \frac{\partial \mathrm{x}}{\partial \mathrm{y}}=1
$$

Along CD

$$
\frac{\mathrm{x}}{\mathrm{P}}=\frac{1}{4 \mathrm{bh}}\left[\mathrm{y}^{3} \frac{\left(\mathrm{h}-\mathrm{a} \tan \frac{\alpha}{2}\right)}{\mathrm{h}^{2}}+\mathrm{y}\left(3 \mathrm{a} \tan \frac{\alpha}{2}+\mathrm{h}\right)\right] \quad \frac{\partial \mathrm{x}}{\partial \mathrm{x}}=0
$$

For the longitudinal shear (mode III) as shown in figure 4 the stress function requirements along the specimen boundary is as follows

Along $\mathrm{AB}$

$$
x=\tau_{\mathrm{xz} 1}\left(\mathrm{r} \sin \varphi+\mathrm{a} \tan \frac{\alpha}{2}\right)
$$

Along BC

$$
\mathrm{X}=\tau_{\mathrm{Xz} 1}\left(\mathrm{~h}+\mathrm{a} \tan \frac{\alpha}{2}\right)
$$

Along CD

$$
x=\tau_{x z 2} r \sin \varphi+h\left(\tau_{x z 1}-\tau_{x z 2}\right)+\tau_{x z 1} a \tan \frac{\alpha}{2}
$$

The detailed derivation of these conditions is given in reference 19. 


\section{REFERENCES}

1. Brown, W. F., Jr.; and Srawley, J. E.: Plane Strain Crack Toughness Testing of High Strength Metallic Materials. Spec. Tech. Publ. No. 410, ASTM, 1967.

2. Anon.: Proposed Method of Test for Plane-Strain Fracture Toughness of Metallic Materials. 1969 Book of ASTM Standards, Part 31, pp. 1099-1114.

3. Gross, Bernard; Srawley, John E.; and Brown, William F., Jr.: Stress-Intensity Factors for a Single-edge-notch Tension Specimen by Boundary Collocation of a Stress Function. NASA TN D-2395, 1964.

4. Brahtz, J. H. A. : Stress Distribution in a Reentrant Corner. J. Appl. Mech. , vol. 1, no. 2, Apr. -June 1933, pp. 31-37.

5. Westergaard, H. M. : Stresses at a Crack, Size of the Crack, and Bending of Reinforced Concrete. J. Am. Concrete Inst., vol. 5, no. 2, Nov./Dec. 1933, pp. 93102.

6. Williams, M. L. : Stress Singularities Resulting From Various Boundary Conditions in Angular Corners of Plates in Extension. J. Appl. Mech., vol. 19, no. 4, Dec. 1952 , pp. $526-528$.

7. Williams, M. L.: On the Stress Distribution at the Base of a Stationary Crack. J. Appl. Mech., vol. 24, no. 1, Mar. 1957, pp. 109-114.

8. Gross, Bernard; and Srawley, John E.: Stress-Intensity Factors for Single-EdgeNotch Specimens in Bending or Combined Bending and Tension by Boundary Collocation of a Stress Function. NASA TN D-2603, 1965.

9. Gross, Bernard; and Srawley, John E. : Stress-Intensity Factors for Three-Point Bend Specimens by Boundary Collocation. NASA TN D-3092, 1965.

10. Gross, Bernard; and Srawley, John E. : Stress-Intensity Factors by Boundary Collocation for Single-Edge-Notch Specimens Subject to Splitting Forces. NASA TN D-3295, 1966.

11. Srawley, John; and Gross, Bernard: Stress Intensity Factors for Crackline-Loaded Edge-Cracked Specimens. Mat. Res. \& Standards, vol. 7, no. 4, Apr. 1967, pp. 155-162; see also NASA TN D-3820, 1967.

12. Gross, Bernard; Roberts, Ernest, Jr.; and Srawley, John E. : Elastic Displacements for Various Edge-Cracked Plate Specimens. Int. J. Fracture Mech., vol. 4, no. 3, Sept. 1968, pp. 267-276; also see NASA TN D-42 32, 1967.

13. Sullivan, A. M.: New Specimen Design for Plane-Strain Fracture Toughness Tests. Mat. Res. \& Standards, vol. 4, no. 1, Jan. 1964, pp. 20-24. 
14. Lubahn, J. D.: Experimental Determination of Energy Release Rate for Notched Bending and Notched Tension. Proc. ASTM, vol. 59, 1959, pp. 885-913.

15. Srawley, John E. ; Jones, Melvin H.; and Gross, Bernard: Experimental Determination of the Dependence of Crack Extension Force on Crack Length for a SingleEdge-Notch Tension Specimen. NASA TN D-2396, 1964.

16. Kobayashi, A. S. : Method of Collocation Applied to Edge Notched Finite Strip Subjected to Uniaxial Tension and Pure Bending. Rep. D2-23551, Boeing Co., Aug. 1964.

17. Wigglesworth, L. A.: Stress Distribution in a Notched Plate. Mathematika, vol. 4, 1957, pp. 76-96.

18. Bueckner, H. F.: Weight Functions for the Notched Bar. Rep. 69-LS-45, General Electric Co., May 12, 1969.

19. Gross, Bernard: Some Plane Problem Elastostatic Solutions for Plates Having a V-Notch. Ph. D. Thesis, Case Western Reserve Univ., 1970.

20. Moser, A. P.: Elastic Stress Fields and Stress Intensity Factor For Finite Bodies. Ph.D. Thesis, Univ. Colorado, 1967.

21. Irwin, G. R. : Analysis of Stresses and Strains Near the End of a Crack Traversing a Plate. J. Appl. Mech., vol. 24, no. 3, Sept. 1957, pp. 361-364.

22. Hulbert, L. E.: The Numerical Solution of Two Dimensional Problems of the Theory of Elasticity. Ph.D. Thesis, Ohio State Univ., 1963. 


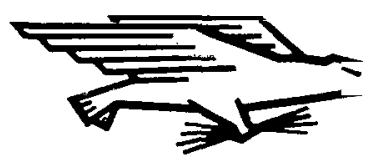

POSTAGE AND FEES PAII NATIONAL AERONAUTICS A SPACE ADMINISTRATION
O2U $00157 \quad 5130 S$

AIR FORCE WEAPONS LABORATORY /WLOL/

KIRTLAND AFB, NEW MEXICO 87117

ATT E. LOU BOWNAN, CHIEF, TECH. LIBRARY

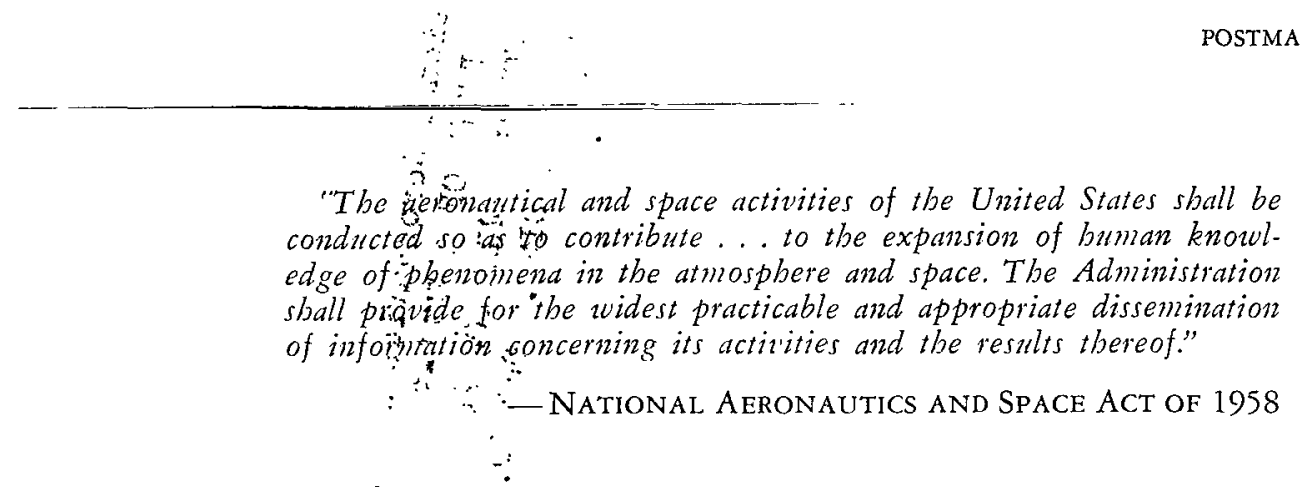

\section{NASA SCIENTIFIC AND TECHNICAL PUBLICATIONS $\because \therefore-$}

TECHNICAL REPORTS广: Scientific and technical information: considered important, complete, and a lasting contribution to existing knowledge."

TECHNICAL NOTES: Information less broad in scope but nevertheless of importance as a contribution to existing knowledge.

TECHNICAL MEMORANDUMS:

Information receiving limited distribution because of preliminary data, security classification, or other reasons.

CONTRACTOR REPORTS: Scientific and technical information generated under a NASA contract or grant and considered an important contribution to existing knowledge.
TECHNICAL TRANSLATIONS: Information published in a foreign language considered to merit NASA distribution in English.

SPECIAL PUBLICATIONS: Information derived from or of value to NASA activities. Publications include conference proceedings, monographs, data compilations, handbooks, sourcebooks, and special bibliographies.

TECHNOLOGY UTILIZATION PUBLICATIONS: Information on technology used by NASA that may be of particular interest in commercial and other non-aerospace applications. Publications include Tech Briefs, Technology Utilization Reports and Notes, and Technology Surveys.

Details on the availability of these publications may be obtained from:

SCIENTIFIC AND TECHNICAL INFORMATION DIVISION

NATIONAL AERONAUTICS AND SPACE ADMINISTRATION Washington, D.C. 20546 